\title{
STRATEGI BISNIS PT CROWDE MEMBANGUN BANGSA DENGAN PENDEKATAN BUSINESS MODEL CANVAS (BMC)
}

\author{
Nanda Putri Astari'1), dan Rita Nurmalina2) \\ 1,2)Departemen Agribisnis, Fakultas Ekonomi dan Manajemen, Institut Pertanian Bogor \\ Jl. Kamper Wing 4 Level 5 Kampus IPB Dramaga Bogor, Indonesia \\ e-mail: 1)astarinandaputri@gmail.com
}

(Diterima 5 agustus 2020 / Revisi 14 Januari 2021 / Disetujui 12 Agustus 2021)

\begin{abstract}
PT Crowde Membangun Bangsa is a financial technology company that offers capital services for agricultural activities. With the concept of peer-to-peer lending (P2P), the company functions as a platform are to bring investors and customers together. To continue to grow and face competition in the future, PT Crowde Membangun Bangsa requires preparation and improvement of business models. This study aims to (1) map the business model applied at PT Crowde Membangun Bangsa, (2) Identify strengths, weaknesses, opportunities, and threats of the nine elements of the Business Model Canvas of PT Crowde Membangun Bangsa, (3) Formulate alternative Business Model strategies The right canvas to be applied to PT Crowde Membangun Bangsa. The data collection method is carried out by direct observation and using the qualitative method. The conclusion of this study is the improvement in the new Business Model Canvas, especially in the customer segment elements by adding plantations as a new segment and beef cattle commodity as an improvement to existing segments so that the company's targets are met. Improvements in these elements need to be supported by improvements from other elements, namely reactivating individual investors as additional corporate financial key resources and types of loan facilities to increase the value proposition and optimizing the use of technology in customer relationship elements and key activities so that additional consumer segments are followed by maximum service and efficient key activities.
\end{abstract}

Keywords: fintech, P2P lending, start up, SWOT

\begin{abstract}
ABSTRAK
PT Crowde Membangun Bangsa merupakan perusahaan berbentuk financial technology yang menawarkan jasa permodalan untuk kegiatan pertanian. Dengan konsep peer to peer lending (P2P), perusahaan berfungsi sebagai platform untuk mempertemukan investor dan pelanggan. Untuk terus berkembang dan menghadapi persaingan PT Crowde Membangun Bangsa memerlukan penyusunan dan perbaikan model bisnis. Penelitian ini bertujuan untuk (1) Memetakan model bisnis yang diterapkan di PT Crowde Membangun Bangsa, (2) Mengidentifikasi kekuatan, kelemahan, peluang, dan ancaman pada sembilan elemen Business Model Canvas PT Crowde Membangun Bangsa, (3) Merumuskan alternatif strategi Business Model Canvas yang tepat untuk diterapkan pada PT Crowde Membangun Bangsa. Metiode pengumpulan data dilakukan dengan observasi langsung, penelitian ini bersifat kualitatif. Kesimpulan dari penelitian ini adalah perbaikan pada Business Model Canvas yang baru terutama pada elemen customer segment dengan melakukan penambahan perkebunan sebagai segmen baru dan komoditas sapi potong sebagai perbaikan dari segmen yang sudah ada agar target perusahaan terpenuhi. Perbaikan pada elemen ini perlu didukung dengan perbaikan elemen lain yaitu mengaktifkan kembali investor perorangan sebagai tambahan financial key resources perusahaan dan jenis fasilitas pinjaman untuk meningkatkan value proposition, serta mengoptimalkan penggunaan teknologi pada elemen customer relationship dan key activities agar tambahan segmen konsumen diikuti dengan layanan yang maksimal dan aktivitas kunci yang efisien.
\end{abstract}

Kata kunci: fintech, P2P lending, start up, SWOT 


\section{PENDAHULUAN}

Pertanian di Indonesia memiliki peran penting bagi perekonomian negara. Pertanian juga menjadi lapangan usaha primer bagi masyarakat Indonesia karena penyerapan tenaga kerja yang cukup besar yaitu 34,58 juta orang atau sebesar 27 persen dari total tenaga kerja (Badan Pusat Statistik, 2019). Walaupun demikian, setiap sub sektor pertanian mulai dari tanaman pangan, holtikultura, perkebunan, kehutanan, peternakan, hingga perikanan memiliki karakteristik dan risiko yang beragam. Karakteristik high risk dan juga masih banyaknya permasalahan menyebabkan sektor pertanian Indonesia tumbuh di bawah pertumbuhan ekonomi Indonesia. Tahun 2019 pertumbuhan perekonomian turun menjadi 5,02 persen, sektor pertanian juga melambat dengan angka 3,64 persen (Badan Pusat Statistik, 2019). Pasaribu (2006) mengatakan salah satu karakteristik penduduk miskin secara spesifik adalah sebagian besar tinggal di pedesaan dengan mata pencaharian dominan di sektor pertanian. Hal ini menyebabkan petani tidak memiliki uang yang cukup untuk menabung dan di investasikan untuk kegiatan pertanian. Kurangnya modal pada kegiatan pertanian menyebabkan sebuah siklus kemiskinan yang terus berulang dan saling mempengaruhi antar komponennya (Gambar 1). Sehingga pengembangan sektor pertanian menjadi sangat penting dalam upaya menurunkan tingkat kemiskinan (Yudhoyono, 2004, Datt dan Ravallion, 1996, serta Matsuyama, 1992).

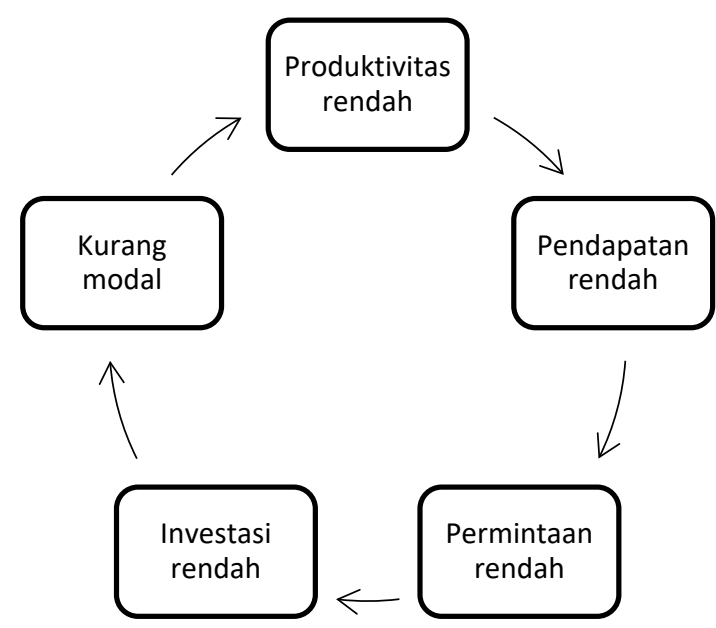

Gambar 1. Siklus Kemiskinan di Perdesaan Sumber : Jhingan (2002)
Salah satu lembaga yang dapat memberikan modal bagi petani adalah lembaga formal seperti bank. Wati (2015) mengatakan rendahnya penyaluran kredit pada sektor pertanian disebabkan sektor pertanian belum memenuhi persyaratan dari bank, adanya perbedaan waktu dalam kegiatan usahatani juga menjadi hambatan bagi petani untuk membayar kredit dengan mekanisme biasa. Sehingga petani membutuhkan alternatif permodalan yang dapat membantu penyelesaian masalah tersebut. Berdasarkan Kajian Stabilitas Keuangan Bank Indonesia (2017) fintech dianggap mampu menjangkau masyarakat yang belum terjangkau oleh lembaga keuangan formal atau perbankan.

Berdasarkan data dari Daily Social Report (2019) investasi yang diberikan pada sektor ini terus meningkat, sepanjang tahun 2019 tercatat sebanyak 23 transaksi pendanaan fintech di Indonesia (Gambar 2). Terdapat 53 start up bidang fintech yang terdaftar di Badan Ekonomi Kreatif (Mapping and Database Start up Indonesia, 2018), PT Crowde Membangun Bangsa merupakan salah satunya. Start up ini menawarkan konsep peer 2 peer lending (P2P) di mana perusahaan berfungsi untuk mempertemukan peminjam (borrower) dan pihak pemberi pinjaman (lender) tanpa harus bertemu langsung (Otoritas Jasa Keuangan, 2018)

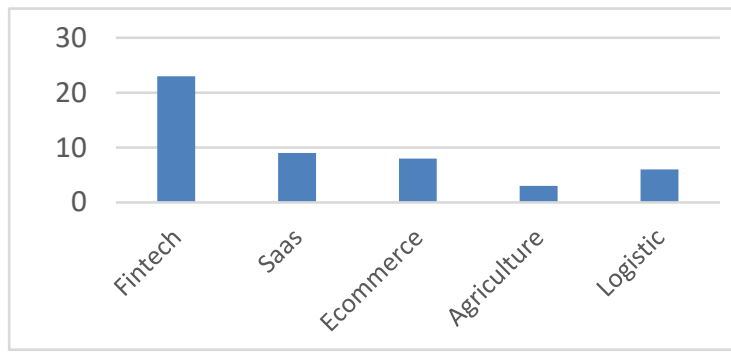

Gambar 2. Transaksi Pendanaan Start Up Sepanjang 2019 Berdasarkan Sektor Bisnis Sumber : Daily Social Report, 2019

Besarnya investasi yang sedang diberikan menjadikan fintech sebagai bidang usaha yang memiliki banyak pesaing, berdasarkan data Asosiasi Fintech Indonesia (AFTECH, 2018) pertumbuhan perusahaan peer to peer lending termasuk yang paling tinggi yaitu sebesar 40 persen. Bertambahnya jumlah perusahaan 
mengakibatkan persaingan pada segmen konsumen meningkat. AFTECH (2018) menyatakan bahwa kenaikan jumlah peminjam sebesar 59,23 persen masih berada di bawah kenaikan jumlah pinjaman yang disalurkan sebesar 97,6 persen. PT Crowde Membangun Bangsa yang juga bergerak dalam bidang ini, perlu memahami setiap komponen dalam model bisnisnya untuk dapat memanfaatkan kekuatan pada perusahaan untuk menangkap peluang yang ada sehingga dapat bersaing dalam pasar, berkembang ke arah yang positif serta dapat menghadapi perubahan dan berinovasi.

Pendanaan pada perusahaan start up fintech yang sedang gencar dilakukan juga menjadikan lingkungan persaingan semakin ketat, terdapat ancaman di mana muncul beberapa start up fintech yang dapat menjadi pesaing bagi PT Crowde Membangun Bangsa (Tabel 1) dengan proposisi nilai yang tidak jauh berbeda. Kondisi Covid-19 juga menjadi salah satu masalah yang dihadapi perusahaan dan sangat berpengaruh pada pencapaian target borrower, sedangan segmen konsumen merupakan aspek terpenting bagi perusahaan. Pemilik perusahaan mengatakan bahwa perusahaan harus memenuhi target sebanyak 100.000 peminjam. Saat ini perusahaan baru memenuhi $30 \%$ dari total target peminjam, belum tercapainya target salah satunya disebabkan oleh kegiatan pemasaran langsung yang dilakukan oleh perusahaan.

Tabel 1. Daftar Start up Fintech Bidang Pertanian

\begin{tabular}{cll}
\hline No & \multicolumn{1}{c}{ Nama } & \multicolumn{1}{c}{ Nama Perusahaan } \\
& Platform & \multicolumn{1}{c}{} \\
\hline 1. & Igrow & PT iGrow Resources Indonesia \\
2. & Iternak.id & PT Perlu Fintech Indonesia \\
3. & TaniFund & PT Tanifund Madani Indonesia \\
4. & Eragano & PT Eragano Agritech Indonesia \\
\hline
\end{tabular}

Sumber : Direktori Fintech OJK, 2019

Kendala yang dihadapi menyebabkan PT Crowde Membangun Bangsa perlu mengevaluasi model bisnis untuk menilai mana bagian yang sudah tidak efektif untuk dijalankan. Jika dilihat dari kondisi perusahaan dan permasalahan yang ada dibutuhkan pembuatan strategi bisnis, menurut David (2016) Strategi adalah sarana bersama dengan tujuan jangka panjang yang hendak dicapai. Strategi bisnis yang diterapkan perushaan tidak dapat berjalan maksimal apabila tidak dilakukan evaluasi dan perumusan model bisnis yang tepat (Chesbrough, 2006). Hal ini menjunjukkan pentingnya strategi bisnis untuk membantu perusahaan memenangkan persaingan serta menjadi acuan perusahaan untuk mengembangkan bisnisnya.

Rukka et al (2018) menyatakan bahwa lingkungan bisnis akan terus berubah, agar bisnis mampu bertahan pada lingkungan tersebut, mereka harus mampu beradaptasi dengan lingkungannya. Perusahan harus mengetahui kondisi bisnisnya secara menyeluruh salah satu caranya dengan memetakan model bisnis perusahaan ke dalam sembilan elemen Business Model Canvas. Menurut Osterwalder dan Pigneur (2016), model bisnis merupakan aktivitas penting dalam manajemen yang sangat memungkinkan organisasi mengevaluasi keadaan usahanya di pasar. PT Crowde Membangun Bangsa juga harus mengetahui kekuatan, kelemahan, peluang, dan ancaman yang terdapat pada tiap elemen model bisnisnya agar perbaikan dapat dilakukan pada tiap elemen model bisnis. Berdasarkan hal tersebut, perlu dilakukan penelitian strategi bisnis PT Crowde Membangun Bangsa dengan pendekatan Business Model Canvas dan matriks SWOT.

Berdasarkan latar belakang dan rumusan masalah yang telah dijabarkan di atas, maka tujuan dari penelitian ini adalah: (1) Memetakan model bisnis yang diterapkan di PT Crowde Membangun Bangsa, (2) Mengidentifikasi kekuatan, kelemahan, peluang, dan ancaman pada sembilan elemen Business Model Canvas berdasarkan PT Crowde Membangun Bangsa, (3) Merumuskan alternatif strategi Business Model Canvas yang tepat untuk diterapkan pada PT Crowde Membangun Bangsa.

\section{METODE}

\section{LOKASI DAN WAKTU PENELITIAN}

Penelitian dilakukan di PT Crowde Membangun Bangsa yang beralamat di Jl. Tebet Raya Nomor 34 Blok A,Tebet, Jakarta Selatan. Proses pengambilan data dalam penelitian ini dilakukan pada bulan Februari-Maret 2020. 
Penelitian mulai tanggal 13 Maret 2020 dilakukan secara online karena kondisi pandemi.

\section{JENIS DAN SUBER DATA}

Jenis data yang digunakan dalam penelitian ini adalah data primer dan data sekunder yang bersifat kualitatif maupun kuantitatif. Data primer diperoleh dari pihak internal perusahaan dan observasi lapang. Sedangkan data sekunder diperoleh dari buku, jurnal, laporan hasil penelitian, situs internet, serta data dari instansi terkait seperti Badan Pusat Statistik, Otoritas Jasa Keuangan dan Badan Ekonomi Kreatif.

\section{METODE PENENTUAN RESPONDEN}

Penentuan responden dalam penelitian ini dilakukan dengan teknik judgement sampling di mana responden merupakan key informan yang lebih mengetahui kondisi perusahaan. Adapun responden dari penelitian ini adalah :

1. Yohanes Sugihtononugroho, sebagai Chief Executive Officer PT Crowde Membangun Bangsa.

2. Raisa Hosin, sebagai Head of Finance PT Crowde Membangun Bangsa

3. Amina Anadia, sebagai Account Officer tim Commercials

4. Satu orang Field Agent Sukabumi dan dua orang petani peminjam (borrower)

\section{METODE PENGUMPULAN DATA}

Teknik pengumpulan data yang digunakan pada penelitian ini adalah observasi langsung ke lokasi perusahaan, melakukan wawancara dengan pihak perusahaan melakukan diskusi mendalam dan data sekunder. Metode pengolahan data yang dilakukan dalam penelitian ini menggunakan analisis deskriptif kualitatif. Metode analisis deskriptif ini diolah atas dasar sembilan elemen Business Model Canvas yang selanjutnya dilakukan analisis SWOT pada masing-masing elemen dalam BMC. Hal ini bertujuan untuk mengevaluasi dan mengetahui kekuatan, kelemahan, peluang dan ancaman dari masing-masing elemen. Pada tahapan analisis matriks SWOT akan dihasilkan empat rumusan strategi alternatif berupa strength-opportunity (SO), weekness-opportunity (WO), strength-opportunity (SO), dan weeknessthreat (WT). Alternatif yang diperoleh dari matriks SWOT selanjutnya akan di aplikasikan kedalam elemen Business Model Canvas perbaikan.

\section{SEJARAH PERUSAHAAN}

PT Crowde Membangun Bangsa didirikan pada tahun 2015, Dengan melihat banyaknya jumlah petani dan juga potensi pertanian yang dimiliki Indonesia, namun petani sendiri masih terkendala permodalan dalam kegiatan budidayanya. Berdasarkan masalah ini, Yohanes mendirikan PT Crowde Membangun Bangsa, yaitu sebuah perusahaan start up fintech yang membawa konsep Crowdfunding dan Peer 2 Peer Lending $(P 2 P)$ di mana Crowde mempertemukan investor dan petani yang membutuhkan modal, konsep ini dirasa cocok untuk membentuk suatu ekosistem permodalan yang berkelanjutan bagi petani.

Sejalan dengan peraturan OJK Nomor 13/POJK.02/2018 tentang Inovasi Keuangan Digital di Sektor Jasa Keuangan di mana seluruh perusahaan berbasis fintech harus mendaftarkan badan usahanya pada 0JK, Crowde resmi terdaftar dengan jenis badan usaha Perseroan Terbatas (PT) dengan jenis perusahaan fintech pada tahun 2018. Kelebihan yang ditawarkan perusahaan ini adalah kemudahan bagi calon peminjam yang sebagian besar merupakan petani untuk mengakses pinjaman. Kebanyakan petani yang masih awam dalam pemenuhan syarat juga ditangani perusahaan dengan melakukan pendampingan oleh pengawas lapang (field agent) yang tersebar di berbagai daerah, Perusahaan juga bekerja sama dengan toko tani untuk memenuhi kebutuhan pupuk dan pestisida petani yang tersebar di berbagai daerah, serta offtaker untuk menampung beberapa hasil panen komoditas yang dibudayakan oleh petani peminjam.

\section{VISI DAN MISI PERUSAHAAN}

Visi PT Crowde Membangun Bangsa adalah merevolusi petani Indonesia. Sedangkan Misi atau strategi yang digunakan untuk mecapai Visi perusahaan adalah sebagai berikut :

1. Memberdayakan petani untuk menjadi agropreneur

2. Menciptakan ekosistem pertanian yang efisien

3. Menjadi platform crowdfunding terpercaya dengan semangat kerja sama timbal balik. 


\section{JENIS FASILITAS PINJAMAN}

1. Bagi Hasil (Profit Sharing) : pada fasilitas ini keuntungan dan risiko di tanggung bersama oleh petani dan investor.

2. Pinjaman (Loan) : peminjam hanya wajib mengembalikan dana sesuai dengan nominal pinjaman yang telah disetujui pada awal kerja sama.

\section{HASIL DAN PEMBAHASAN}

\section{BUSINESS MODEL CANVAS (BMC) \\ Customer Segment}

PT Crowde Membangun Bangsa memiliki segmen pelanggan yang termasuk dalam tipe tersegmentasi dengan rincian senagai berikut :

1. Petani Holtikultura dan tanaman pangan: Komoditas cabai, sawi, mentimun, padi dan jagung. Segmen ini termasuk yang paling banyak ditargetkan karena siklus budidaya yang tidak terlalu lama serta permintaan pasar yang cukup tinggi.

2. Peternakan : Komoditas domba dan kambing. Segmen ini memiliki kelebihan risiko yang lebih rendah dibandingkan petani budidaya maupun perikanan.

3. Perikanan : Segmen ini memiliki kebutuhan yang cukup besar dan juga waktu yang lama, saat ini komoditas udang masih menjadi salah satu komoditas unggulan.

4. Perdagangan : Segmen ini memiliki jumlah pinjaman yang cukup besar dibandingkan dengan segmen lainnya karena dana pinjaman digunakan untuk kegiatan usaha.

\section{Value Proposition}

Menurut Osterwalder dan Pigneur (2016), Value propositions merupakan kumpulan produk atau jasa yang ditawarkan dan memberikan nilai terhadap targer pelanggan yang spesifik. Nilai utama yang ditawarkan kepada pelanggan adalah kemudahan dalam mengakses pinjaman, di mana petani yang sebelumnya terkendala akses pinjaman lembaga keuangan formal dapat mengajukan pinjamannya sesuai dengan jenis fasilitas pinjaman yang disediakan dengan lebih mudah.

\section{Channels}

Terdapat dua saluran pemasaran pada perusahaan. Saluran langsung berupa pemasaran dan kunjungan langsung serta monitoring yang dilakukan field agent. Pada saluran tidak langsung, pelanggan mendapatkan informasi tentang perusahaan melalui Instagram, Website, layanan Customer Service, dan juga Whatsapp. Salah satu ciri perusahaan start up adalah digitalisasi atau penggunaan teknologi yang dapat mempermudah kebutuhan pelanggannya. Pada Tabel 2 dijelaskan 5 fase dalam saluran pemasaran PT Crowde Membangun Bangsa.

\section{Tabel 2. Fase Saluran Pemasaran PT Crowde} Membangun Bangsa

\begin{tabular}{|c|c|}
\hline $\begin{array}{l}\text { Fase saluran } \\
\text { Pemasaran }\end{array}$ & Deskripsi \\
\hline 1. Awarness & $\begin{array}{l}\text { Pemasaran langsung dan tidak } \\
\text { langsung }\end{array}$ \\
\hline 2. Evaluation & $\begin{array}{l}\text { Negosiasi jumlah pinjaman } \\
\text { dan RAB }\end{array}$ \\
\hline 3. $P r$ & Tanda tangan kontrak \\
\hline 4. $D$ & Penyaluran dana \\
\hline 5. Aftersales & $\begin{array}{l}\text { Recurring, Refinancing, dan } \\
\text { collection }\end{array}$ \\
\hline
\end{tabular}

\section{Customer Relationship}

Jenis hubungan yang dibangun oleh PT Crowde Membangun Bangsa adalah bantuan personal yang didasarkan pada hubungan interaksi antar manusia. Faslitas yang disediakan untuk berhubungan dengan pelanggan adalah email dan telepon serta whatsapp grup. Sedangkan secara langsung dilakukan dengan kunjungan berkala hingga acara dan pelatihan bagi field agent dan peminjam yang berhasil dalam menjalankan kegiatan budidayanya.

\section{Revenue Streams}

PT Crowde Membangun Bangsa memperoleh pendapatan dari pemberian pinjaman kepada segmen pelanggan yang mereka layani dengan bentuk service charge sebesar 5 persen pada setiap pinjaman. Berdasarkan jumlah peminjam, segmen yang memberikan kontribusi terbesar adalah budidaya holtikultura dan tanaman pangan dengan persentase 50 persen, diikuti dengan perikanan sebesar 20 persen, peternakan sebesar 20 persen, dan perdagangan 
10 persen. Perbedaan ini disebabkan pemasaran yang dilakukan perusahaan masih terfokus di daerah Jawa Barat dan sebagian besar petani berada pada segmen tersebut.

\section{Key Resources}

Sumber daya utama yang dimiliki PT Crowde Membangun Bangsa adalah sebagai berikut :

1. Sumber daya fisik : Dua gedung kantor, peralatan kantor, serta mobil operasional.

2. Sumber daya manusia : 67 karyawan yang dibagi ke dalam delapan divisi.

3. Sumber daya modal : Modal pribadi serta investasi dari delapan investor institusional.

\section{Key Activities}

Aktivitas kunci yang dilakukan perusahaan untuk menyampaikan proporsisi nilainya adalah sebagai berikut :

1. Pencarian proyek/peminjam : Dilakukan dengan pemasaran secara online dan offline. Pemasaran secara offline lebih banyak dilakukan.

2. Pengisian data : Data yang harus dipenuhi adalah dokumen KTP, kartu keluarga, dan nomor rekening. Serta mengisi jumlah pinjaman, RAB dan jenis fasilitas pinjaman.

3. Input data dan analisis risiko : Data akan dimasukan ke dalam database dan dilakukan BI Checking serta analisis risiko apakah peminjam memenuhi kualifikasi.

4. Perjanjian kerja sama : Peminjam yang sesuai kualifikasi akan dibuatkan perjanjian kerja sama atau konrak sesuai dengan detail pinjaman yang telah disetujui.

5. Penyaluran dana dan monitoring : Penyaluran dana dilakukan secara parsial atau menyeluruh sesuai dengan kebutuhan peminjam. Selama proses budidaya berlangsung, perusahaan bertanggung jawab untuk memonitoring berjalannya kegiatan tersebut.

6. Repayment : Pembayaran pinjaman sesuai dengan jumlah dan jenis fasilitas pinjaman yang dipilih.

7. Collection : Penyelesaikan pinjaman yang sudah lewat dari tanggal jatuh tempo.

\section{Key Partnership}

PT Crowde Membangun Bangsa menjalin hubungan kemitraan dengan jenis aliansi strategis non pesaing dengan beberapa mitra untuk membantu berjalannya model bisnis mereka. Hubungan kemitraan dengan toko tani didasari atas motivasi pengurangan risiko dan ketidakpastian, sedangkan dengan pihak offtaker dan investor didasari pengurangan risiko dan ketidakpastian serta optimisasi dan skala ekonomi. Rincian mitra yang bekerja sama dengan PT Crowde Membangun Bangsa dapat dilihat pada Tabel 3.

Tabel 3. Mitra yang Bekerjasama dengan PT Crowde Membangun Bangsa

\begin{tabular}{ll}
\hline Jenis Mitra & \multicolumn{1}{c}{ Rincian } \\
\hline Toko tani & 26 toko tani di Jawa Barat, Jawa \\
& Timur, Jawa Tengah, Nusa \\
& Tengga Barat, Sumatera Utara, \\
& dan Lampung. \\
Investor & Bank Mandiri, Bank BJB, Bank \\
Institusional & BRI, Saison Modern Finance, \\
& Jasindo Syariah, Eight Four \\
& Capital, IFC, GREE Ventures \\
Offtaker & Indofood, Japfa Comfeed \\
& Indonesia, PT Petani Ceria \\
& Sejahtera \\
\hline
\end{tabular}

Sumber : PT Crowde Membangun Bangsa, 2020

\section{Cost Stucture}

PT Crowde Membangun Bangsa Memiliki struktur terpacu biaya (cost driven) di mana perusahaan berusaha untuk meminimalkan biaya yang dikeluarkan untuk memaksimalkan pendapatan. Struktur biaya PT Crowde Membangun Bangsa dapat dilihat pada tabel 4 di mana persentase biaya tetap dan biaya variabel sangat signifikan di mana biaya tetap hanya memiliki persentase sebesar $10 \%$ sedangkan biaya variabel sebesar $90 \%$.

\begin{tabular}{|c|c|}
\hline Uraian & $\begin{array}{c}\text { Persentase } \\
\text { Pengeluaran }\end{array}$ \\
\hline \multicolumn{2}{|l|}{ Biaya Tetap } \\
\hline Sewa Kantor & $5 \%$ \\
\hline Sewa Peralatan & $5 \%$ \\
\hline \multicolumn{2}{|l|}{ Biaya Variabel } \\
\hline Gaji Karyawan & $30 \%$ \\
\hline Operasional Perusahaan & $15 \%$ \\
\hline Asuransi & $10 \%$ \\
\hline Pengembangan Teknologi & $35 \%$ \\
\hline Total Pengeluaran & $100 \%$ \\
\hline
\end{tabular}

Sumber : Data diolah, 2020 


\section{EVALUASI BMC DENGAN ANALISIS SWOT}

Tahap selanjutnya adalah mengevaluasi model bisnis dengan menggunakan analisis SWOT yang memungkinkan penilaian yang terfokus pada tiap elemen BMC.

\section{Strengh}

1. Pelanggan telah tersegmentasi : Perusahaan sudah mampu membagi dan melayani 4 segmen dengan kebutuhan yang berbeda.

2. Kemudahan syarat dalam pengajuan pinjaman: Petani akan dibantu oleh field agent dalam pemenuhan syarat pinjaman. Peraturan serta jumlah pinjaman juga lebih fleksibel dibandingkan dengan bank sehingga pelanggan dapat mengajukan pinjaman sesuai dengan kebutuhannya.

3. Perusahaan sudah memiliki investor tetap : Perusahaan telah mendapatkan pendanaan tetap dari 8 investor institusional sehingga kegiatan operasional dapat terus berjalan tanpa harus khawatir akan kekurangan modal.

4. Mitra yang terletak di berbagai daerah mempermudah kegiatan operasional : Penyaluran dana dan kebutuhan lebih cepat dilakukan sesuai dengan daerah peminjam.

\section{Weakness}

1. Kegiatan pemasaran memerlukan banyak biaya : pemasaran yang dilakuan secara langsung ke berbagai daerah memerlukan biaya yang cukup besar.

2. Branding perusahaan yang lemah : Intagram dan website belum termanfaatkan sebagai media branding yang dengan baik karena data yang ditampilkan bukan data terbaru serta investor yang belum menerima pengembalian dana karena kegiatan budidaya yang gagal dapat menurunkan kepercayaan terhadap perusahaan. Walaupun saat ini sedang dilakukan proses pengembalian dana oleh perusahaan.

3. Pendapatan hanya berasal dari satu sumber: Pendapatan hanya berasal dari service charge atau biaya layanan untuk tiap pinjaman berjalan.

4. Masa kerja sumber daya manusia yang pendek: Hal ini menjadi kelemahan karena semakin singkat masa kerja maka transisi pekerjaan akan sering dilakukan dan mengurangi efisiensi aktivitas kunci.

5. Pelaksanaan aktivitas kunci belum efisien : Alur informasi belum tertata rapih sehingga masih terjadi perbedaan informasi.

6. Biaya variabel perusahaan belum proporsional: Dapat dilihat pada tabel 4, biaya pengembangan teknologi memiliki persentase yang jauh lebih besar pada biaya variabel.

\section{Opportunity}

1. Beragamnya pelaku sektor pertanian di Indonesia : Kegiatan sektor pertanian terbagi mulai hulu hingga hilir, dalam prosesnya banyak pelakaku usaha pertanian yang terlibat.

2. Kurangnya akses petani terhadap lembaga keuangan formal : adanya kondisi ini dapat menjadi peluang bagi perusahaan dengan menawarkan proposisi nilai yang sesuai dengan permasalahan yang dialami petani.

3. Perkembangan teknologi yang semakin pesat : Jika perusahaan dapat memanfaatkan peluang ini dengan baik, kuantitas dan kualias layanan yang diberikan perusahaan akan semakin optimal.

4. Peningkatan pendanaan bagi start up : pada gambar 2 dapat dilihat bahwa sektor fintech masih mendaptkan pendanaan terbesar. Menurut data statistik fintech yang dikeluarkan oleh OJK pada bulan Maret 2020 investor di daerah Jawa memiliki persentase terbesar dengan angka 37\% dengan DKI Jakarta sebagai penyumbang terbanyak.

5. Kolaborasi dengan mitra utama : Kolaborasi dapat dilakukan dengan mengintegrasikan kegiatan budidaya mulai dari hulu hingga hilir.

\section{Threat}

1. Persaingan yang tinggi antar fintech sejenis : Pada tabel 1 dapat dilihat bahwa perusahaan memiiki pesaing dengan proposisi nilai yang tidak jauh berbeda.

2. Kompetisi yang tinggi terhadap akusisi sumberdaya dengan pesaing : modal dan sumber daya manusia masih menjadi masalah utama yang dialami oleh perusahaan start up sehingga kederadaanya diperebutkan. 
3. Hubungan dengan investor yang terganggu jika banyak proyek gagal : Jika pinjaman gagal investor tidak mendapatkan keuntungan yang diharapkan dan berakibat pada hubungan dengan perusahaan.

\section{ALTERNATIF STRATEGI PADA BMC}

Pada tahap ini dilakukan pencocokan unsur kekuatan-kelemahan dan peluang-ancaman yang ada pada elemen BMC. Sehingga dihasilkan rumusan alternatif berupa strategi SO, WO, ST, dan WT yang akan diterapkan pada sembilan unsur BMC. Adapun penerapan strategi dalam perbaikan model bisnis adalah sebagai berikut :

\section{Customer Segment}

Strategi yang dapat diterapkan pada blok ini adalah S0-1 yaitu meningkatkan segmen konsumen dengan menambah segmen dan jenis komoditas. Permadi, Nurmalina, dan Kirbrandoko (2016) juga menerapkan strategi ini untuk memperluas segmentasi konsumen perusahaan. Adapaun tambahan segmen tersebut adalah :

1. Perkebunan : jumlah rumah tangga pertanian dengan perkebunan sebagai jenis usaha utama yang diusahakan berjumlah 6.863.285 menjadikan peluang mendapatkan tambahan peminjam lebih besar (SUTAS, 2018). Kharisma dan Nur (2019) menyatakan bahwa Jawa Barat memiliki empat komoditas perkebunan yang memiliki potensi tinggi yaitu Lada, Nilam, Pala, dan Aren. Tambahan segmen perkebunan juga didasari atas risiko pada kegiatan budidaya yang lebih rendah dari tanaman holtikultura dan tanaman pangan.

2. Komoditas sapi potong pada segmen peternakan : risiko lebih rendah dengan 4.526.960 rumah tangga petani mengusahakan komoditas ini, lebih besar jumlahnya dari komoditas kambing dan domba yang sedang dilayani (SUTAS, 2018).

\section{Value Proposition}

Strategi ST-1 dapat diterapkan oleh perusahaaan dengan mengembangkan fasilitas pinjaman serta penawaran nilai yang berbeda dari perusahaan sejenis.

1. Jenis fasilitas : Pembiayaan skema Syariah
2. Value proposition : kemudahan petani dalam mengakses pasar dan bimbingan bagi petani. Kosasi (2015) juga menjadikan accessibility (kemudahan mengakses) sebagai tambahan nilai yang ditawarkan oleh perusahaan.

\section{Channels}

Strategi WO-1 dengan penyesuaian saluran pemasaran dengan segmen pelanggan. Perusahaan sudah memiliki mitra dan juga pengawas lapang yang berpengalaman sehingga dapat dilakukan kerja sama agar mitra dan pengawas lapang juga turut memasarkan jasa yang ditawarkan perusahan. Strategi selanjutnya adalah SO-2 yaitu memaksimalkan saluran pemasaran secara online, dapat dilakukan dengan membuat konten interaktif dan juga menampilkan kegiatan yang dilakukan perusahaan dalam kegiatan pertanian.

\section{Customer Relationship}

Pada blok ini perusahaan dapat menerapkan strategi WO-2 dengan penggunaan teknologi untuk meningkatkan pelayanan. Pembuatan layanan otomartis sangat membantu hubungan perusahaan dengan pelanggan jika terdapat tambahan jumlah peminjam, sehingga tiap peminjam dapat terlayani dengan baik dan cepat. Hubungan kokreasi juga dapat diterapkan untuk mendapatkan timbal balik dan evaluasi dari peminjam terkait dengan layanan perusahaan. Luthan, Winandi, dan Rifin (2019) juga menggunakan jenis hubungan ini untuk meningkatkan kepuasan konsumen.

\section{Revenue Streams}

Agar target perusahaan terpenuhi, strategi WO-3 yaitu kolaborasi dan tambahan mitra. Perusahaan bisa mendapatkan pemasukan tambahan yang berasal dari kerja sama dengan mitra baru, contohnya adalah UMKM pengolahan di mana perusahaan mendapatkan pemasukan dari hasil penjualan pengolahan hasil panen tersebut. Penerapan strategi ini juga mendukung peningkatan proposisi nilai perusahaan dengan menerapkan konsep from farm to fork. 


\section{Key Resources}

Pada blok ini perusahaan dapat menerapkan strategi WT-2 dengan pemberian pelatihan sehingga pegawai akan mendapat kesempatan untuk berkembang dan meningkatkan kualitas diri, jadi pihak pegawai juga mendapatkan keuntungan dari perusahaan selain gaji yang diberikan. Strategi WO-4 juga dapat diterapkan yaitu mengaktifkan kembali investor perorangan dapat dilakukan untuk meningkatkan sumberdaya finansial perusahaan.

\section{Key Activities}

Pada aktivitas kunci strategi WT-1 dapat dilakukan, tambahan segmen konsumen serta komoditas baru harus diimbangi analisis risiko dan juga monitoring yang ketat sehingga kualitas dan kuantitas peminjam terpenuhi. Strategi ini dilakukan agar persentase pinjaman berhasil meningkat dan tidak menghambat proses pengembalian dana (repayment). Dengan bertambahnya peminjam, perusahaan harus mampu menyelesaikan rangkaian aktivitas kunci secara efektif agar proposisi nilai dapat tersalurkan dengan baik. Bantuan teknologi seperti sistem ataupun aplikasi yang membantu untuk menginput data, proses penyaluran dana, hingga kegiatan monitoring akan sangat mempersingkat dan menjadikan aktivitas kunci lebih efektif dengan kualitas dan kapasitas yang maksimal.

\section{Key Partnership}

Untuk mendukung bisnis perusahaan, strategi yang dapat dilakukan adalah WO-3, perusahaan perlu menjalin kerja sama dengan offtaker untuk menampung hasil panen segmen perkebunan untuk meminimalisir risiko fluktuasi harga. Tambahan mitra berupa perusahaan atau UMKM pengolahan yang dapat menampung hasil panen petani yang bekerja sama dengan perusahaan terlebih petani holtikultura dengan hasil panen yang mudah rusak. Adanya kerja sama juga dapat menguntungkan perusahaan untuk memasarkan produknya (Disa, Nurmalina, dan Syuaib, 2015). Berdasarkan data SUTAS tahun 2018 hanya sebesar 3,09 persen rumah tangga petani holtikultura yang mengolah hasil panennya sendiri, hal ini dapat menjadi peluang bagi perusahaan. Koordinasi antar mitra mulai dari pengadaan input (Toko Tani) hingga pengolahan dapat dilakukan agar kegiatan pertanian terintegrasi dan memberikan nilai lebih yang ditawarkan perusahaan. Strategi selanjutnya adalah WO-4, pengaktifan investor perorangan akan menambah mitra dan meningkatkan brand awarness perusahaan agar lebih banyak lagi pihak yang mengetahui keberadaan PT Crowde Membangun Bangsa.

\section{Cost Structure}

Perlu diterapkan strategi WO-5 yaitu pembuatan budgeting yang efektif dan efisien dan prioritas investasi, perusahaan harus menentukan biaya mana yang harus di keluarkan terlebih dahulu. Untuk biaya pemasaran perlu dibuat skala prioritas perdaerah untuk menentukan alokasi biaya pemasaran yang perlu diprioritaskan dan memberikan hasil yang sebanding. Sedangkan untuk biaya pengembangan teknologi yang cukup besar, dapat dibuat rencana jangka pendek dan jangka panjang agar biaya yang dikeluarkan dapat tertata dan pengembangan teknologi yang dilakukan akan dievaluasi apakah memberikan dampak yang signifikan pada efisiensi aktivitas kunci.

Secara garis besar strategi yang dapat diterapkan adalah penambahan segmen dan juga jenis komoditas, peningkatan value propositions dengan adanya variasi jenis fasilitas pinjaman dan perbedaan nilai yang ditawarkan, dibantu dengan channels yang efektif dalam menjangkau pelanggan, customer relationship yang baik sehingga pelanggan loyal bertambah dan meningkatkan pendapatan pada revenue streams, pentingnya key resources, key activities, dan key partnership untuk mendukung strategi bisnis, hingga perlunya perencanaan biaya yang efektif dan efisien pada cost structure PT Crowde Membangun bangsa untuk membantu prioritas investasi.

\section{SIMPULAN DAN SARAN}

\section{SIMPULAN}

1. Berdasarkan hasil pemetaan model bisnis saat ini, terdapat beberapa elemen yang sudah baik dan perlu dipertahankan namun terdapat pula elemen yang harus diperbaiki terutama 
customer segment yang berdampak pada belum tercapainya target perusahaan dan revenue streams yang belum optimal.

2. Analisis SWOT pada business model canvas perusahaan menghasilkan empat strategi yaitu strategi SO diprioritaskan untuk peningkatan segmen konsumen dan mitra perusahaan, untuk strategi ST digunakan untuk memperbaiki value proposition yang ditawarkan, strategi WO dengan fokus peningkatan efisiensi pemasaran dan aktivitas kunci, dan strategi WT yang berfokus meningkatkan kualitas peminjam dan SDM perusahaan

3. Adanya perbaikan pada business model canvas yang baru terutama pada elemen customer segment dengan melakukan penambahan perkebunan sebagai segmen baru dan komoditas sapi potong sebagai perbaikan dari segmen yang sudah ada agar target perusahaan terpenuhi, perbaikan pada elemen ini perlu didukung dengan perbaikan elemen lain yaitu mengaktifkan kembali investor perorangan sebagai tambahan financial key resources perusahaan, tambahan jenis fasilitas pinjaman untuk meningkatkan value proposition, serta mengoptimalkan penggunaan teknologi pada elemen customer relationship dan key activities agar tambahan segmen konsumen diikuti dengan layanan yang maksimal dan aktivitas kunci yang efisien

\section{SARAN}

1. PT Crowde Membangun Bangsa perlu berfokus pada peningkatan jumlah peminjam dengan menerapkan saluran pemasaran yang sesuai dan diikuti dengan peningkatan analisis risiko dan monitoring agar peminjam yang dibiayai perusahaan berkualitas dan keberhasilan pinjaman dapat meningkat.

2. Untuk membantu meningkatkan pemasukan, perusahaan dapat berkolaborasi dengan UMKM pengolahan ataupun masyarakat sekitar untuk mengolah hasil panen. Selain mengurangi risiko, kegiatan ini juga menjadi diversivikasi pemasukan bagi perusahaan agar tidak bergantung pada biaya layanan saja.

3. Adanya perbaikan pada elemen BMC akan memengaruhi cost structure perusahaan, sehingga perlu dilakukan pemetaan prioritas investasi dengan tujuan pengeluaran yang dilakukan untuk perbaikan model bisnis dapat terarah sesuai dengan kebutuhan utama perusahaan.

\section{DAFTAR PUSTAKA}

[BPS]. Badan Pusat Statistik. 2020. Pertumbuhan Ekonomi Indonesia, 2020. [Internet]. [diunduh 2020 Februari 15]. Tersedia pada : https://www.bps.go.id/pressrelease/2020/ 02/05/1755/ekonomi-indonesia-2019tumbuh-5-02-persen.htmlGujarati DN. 2010. Dasar-Dasar Ekonometrika Buku I. Jakarta (ID): Penerbit Salemba.

Chesbrough, HW. 2006. Open Business Models: How to Thrive in The New Innovation Landscape. Boston: Harvard Business School Press.

[DSR]. Daily Social Report. 2020. Pendanaan Start up Berdasarkan Sektor Bisnis, 2019. [Internet]. [diunduh 2020 Februari 18]. Tersedia pada https://dailysocial.id/post/pendanaanstartup-indonesia-2019. Oster

Datt G, Ravallion M. 1996. How Important to India's Poor is the Sectoral Composition of Economic Growth?: The World Bank Economic Review.

David FR. 2016. Manajemen Strategik. Ed ke-15. Puspasari LN, penerjemah, Jakarta (ID) : Salemba Empat. Terjemahan dari : Stretegic Manajemen : A Competitive Advantage Approach, Concept and Cases, 15 th ed.

Disa AA, Nurmalina R, Syuaib MF. 2015. Analysis of Business Model Development of Honey Product Using Business Model Canvas Approach. International Journal of Science and Research (IJSR). 6 (8): 262-267.

Kharisma B, Nur YH. 2019. Penentuan komoditas perkebunan unggulan di provinsi jawa barat. Jurnal trunojoyo. 14 (1): 73-104

Kosasi, VM. 2015. Analisis dan Evaluasi Model Bisnis pada Pantai Seafood Restaurat dengan Pendekatan Business Model Canvas. AGORA. 3(1): 314-323. 
Luthan MZ, Winandi R, Rifin A. 2019. Analisis Pengembangan Bisnis Kanvas Perusahaan Holtikultura PT XYZ. Forum Agribisnis. 9(2): 185-199.

Matsuyama K. 1992. Agriculture Productivity, Comparative Advantage and Economic Growth: Journal of Economic Theory.

Osterwalder A, Pigneur Y. 2019. Business Model Canvas. Ed ke-10. Natalia RS, penerjemah. Jakarta (ID) : Gramedia. Terjemahan dari : Business Model Canvas, 10th ed.

Permadi B, Nurmalina R, Kirbrandoko. 2016. Analisis pengembangan Model Bisnis Kanvas CV Kandura Keramik Bandung. Jurnal Aplikasi Manajemen. 14 (1):88-96.

Pasaribu B. 2006. Poverty Profile and Alleviation Programs in Indonesia. Paper presented in Asian Regional Seminar on Poverty Alleviation, held by AFPPD and IFAD. Hanoi, Vietnam.

Rukka RM, Busthanul N, Antonny N. 2018. Startegi Pengembangan Bisnis Keripik Bayam dengan Pendekatan Business Model Canvas : Studi kasus pada CV. OAG di Kota Makassar, Sulawesi Selatan. Jurnal Sosial Ekonomi Pertanian. 14(1):41-54

Wati DR. 2015. Akses kredit mikro pada petani padi organic di kabupaten bogor. Jurnal agribisnis. 9 (2): 97-110.

Yudhoyono SB. 2004. Pembangunan Pertanian dan Perdesaan Sebagai Upaya Mengatasi Kemiskinan dan Pengangguran: Analisis Ekonomi Politik Kebijakan Fiskal [Disertasi]. IEPIPB. Bogor. 